\title{
EDUCAÇÃO PERMANENTE EM SAÚDE: UMA EXPERIÊNCIA DO PROJETO “BIOÉTICA PELAS LENTES DO CINEMA"
}

\author{
Juliara Bellina Hoffmann \\ Universidade Federal de Santa Catarina \\ juliara.odt@gmail.com
}

\author{
Lucas Berté Moratelli \\ Universidade Federal de Santa Catarina \\ lucasmoratelli3@gmail.com \\ Mirelle Finkler \\ Universidade Federal de Santa Catarina \\ mirellefinkler@yahoo.com.br
}

\section{Resumo}

Este trabalho objetivou refletir e compartilhar a experiência de educação permanente com estudantes da Residência Multiprofissional em Saúde da Família da Prefeitura Municipal de Florianópolis, por meio da Bioética Narrativa. O Núcleo de Pesquisa e Extensão em Bioética e Saúde Coletiva/UFSC realizou no segundo semestre de 2016 o projeto de extensão "Bioética pelas Lentes do Cinema", em parceria com a Secretaria de Saúde Municipal, ofertando-o para 47 profissionais residentes. Utilizou-se o cinema como recurso pedagógico para disparar a problematização da realidade e ancoragem dos argumentos de reflexão, construindo-se um espaço pedagógico de ensino-aprendizagem na aproximação do vivenciado no filme e o racionalizado em conjunto. Considerou-se que o projeto contribuiu significativamente para formação dos residentes e membros do Núcleo, especificamente, no desenvolvimento de sua capacidade crítica e reflexiva. Também permitiu evidenciar como a racionalidade narrativa auxilia a tomada de decisão frente às problemáticas éticas presentes no cotidiano do trabalho em saúde.

Palavras-chave: Ética. Bioética. Educação. Cinema.

\section{PERMANENT HEALTH EDUCATION: AN EXPERIENCE OF THE PROJECT "BIOETHICS BY THE CINEMA LENSES"}

Abstract

The study reflects and shares the permanent education experience with students of the Multiprofessional Residency in Family Health of the Municipality of Florianopolis and through the Bioethics Narrative. In the second half of 2016, the Nucleus of Research and Extension in Bioethics and Collective Health/UFSC carried out the extension project "Bioethics by the Cinema Lenses" in partnership with the Municipal Health Secretary, and it was offered to 47 resident professionals. The cinema was used as a pedagogical resource to trigger the reality problematization and anchor reflection arguments, constructing an educational space of teaching-learning regarding the movie experience and group rationalization. The project contributed significantly to the training of residents and members of the Nucleus, specifically, in developing their critical and reflective capacities. It also allowed highlighting how the narrative rationality helps decision making in the face of ethical problems present in the daily life of health work.

Keywords: Ethic. Bioethics. Education. Movie theater.

\section{EDUCACIÓN PERMANENTE EN SALUD: UNA EXPERIENCIA DEL PROYECTO "BIOÉTICA POR LAS LENTES DEL CINE"}

\section{Resumen}

El objetivo de este estudio es reflexionar y compartir la experiencia de educación permanente con estudiantes de la Residencia Multiprofesional en Salud de la Familia de la Prefectura Municipal de Florianópolis, por medio de la Bioética Narrativa. El Núcleo de Investigación y Extensión en Bioética y Salud Colectiva / UFSC realizó en el segundo semestre de 2016 el proyecto de extensión "Bioética por las Lentes del Cine", en asociación con la Secretaría de Salud Municipal, ofreciéndolo a 47 profesionales residentes. Se utilizó el cine como recurso pedagógico para disparar la problematización de la realidad y anclaje de los argumentos de reflexión, construyendo un espacio pedagógico de enseñanza-aprendizaje en la aproximación de lo vivido en la película y lo racionalizado en conjunto. Se consideró que el proyecto contribuyó significativamente a la formación de los residentes y miembros del Núcleo, específicamente, en el desarrollo de su capacidad crítica y reflexiva. También permitió evidenciar cómo la racionalidad narrativa auxilia la toma de decisión frente a las problemáticas éticas presentes en el cotidiano del trabajo en salud.

Palabras clave: Ética. Bioética. Educación. Cine. 
Educação permanente em saúde: uma experiência do projeto "Bioética pelas lentes do Cinema"

\section{INTRODUÇÃO}

O desenvolvimento da capacidade de reflexão, crítica e autocrítica no espaço universitário está intimamente ligado à formação ética dos estudantes, que se caracteriza pelo seu desenvolvimento moral à medida que adquirem conhecimentos e desenvolvem habilidades e atitudes para lidar com os problemas éticos presentes em seu contexto (FINKLER; CAETANO; RAMOS, 2012). O desenvolvimento moral e, portanto, a educação para o mundo dos valores exige que adentremos no mundo humano real e cotidiano, e implica na participação ativa dos estudantes na construção de seu próprio saber (GRACIA, 2000).

Essa construção encontra maiores dificuldades em "sociedades da informação" como as nossas, em que a cultura positivista relega o relato, a narrativa, a experiência humana ao domínio da subjetividade. Vivemos na era da informação, mas não da experiência, o que se reflete na oposição entre cultura científica e humanística (DOMINGO; FEITO, 2013), levando a uma formação em saúde em que prevalecem constantemente os aspectos técnicos-científicos sobre os ético-sociais (FINKLER; CAETANO; RAMOS, 2012).

Para Gracia (2000) é possível aprender a ser ético desde que nos espaços educativos haja maior atenção às possibilidades de ensino de determinados conhecimentos e habilidades, e não de 'receitas' prescritivas desta ou daquela atitude. Para tanto, o ensino da bioética se apresenta como ferramenta capaz de auxiliar nas tomadas de decisão dos profissionais da saúde. Contudo, seu ensino está muito além da inclusão de uma disciplina, pois depende de uma transformação cultural em que a preparação de profissionais esteja diretamente ligada à educação de cidadãos (MARTÍNEZ; ESTRADA; BARA, 2002).

Pensar um método de ensino ético-humanístico exige do corpo docente criatividade, flexibilidade, abertura, e capacidade de observação e interação, fugindo do meio aséptico do ensino biologicista. Este movimento que repensa os métodos educacionais tem encontrado nas mais variadas narrativas (novelas, contos, relato fílmico, autobiografia, histórias pessoais e clínicas) um modo de compartilhar conhecimentos e experiências que servem como veículos de cultura, tradição e valores (DOMINGO; FEITO, 2013).

Neste leque de possibilidades narrativas, o uso de produções cinematográficas tem servido como recurso pedagógico bastante difundido no processo de ensino-aprendizagem de bioética, principalmente por propiciar a problematização da realidade e ancorar argumentos da reflexão e discussão. O cinema expõe uma cirscuntancia expecífica, uma forma de pensar uma condição e refletir sobre ela, possibilitando hábitos mentais mais 
Educação permanente em saúde: uma experiência do projeto "Bioética pelas lentes do Cinema"

imaginativos e criativos. Essa racionalidade narrativa permite pensar as atitudes humanas, as vissitudes, as intenções, ações e suas consequências, sendo inegável a aproximação das narrativas cinematográficas do ensino da bioética: o cinema torna-se instrumento pelo qual a bioética navega pela complexidade humana (DOMINGO, 2011).

O objetivo da Bioética Narrativa é o exercício de julgamento moral, decidir não se atendo somente a fatos, mas também a valores. A função do uso do cinema é desnudar a própria existência humana como narrativa - temporal, circunstancial, concreta, repleta de emoção e de vida - permitindo o distanciamento das margens estreitas dentro das quais a sociedade tem pensado a razão. É na aproximação com o vivenciado no filme e o racionalizado em conjunto que se constrói um espaço pedagógico de ensino-aprendizagem.

Apesar de sua propagação, ainda há uma subutilização do cinema enquanto recurso pedagógico, tornando-o meio para 'opinar' sobre temas bioéticos, forma de manipulação ideológica ou de simples entretenimento. A questão é que mesmo o cinema 'dando o que pensar', o processo de aprendizagem não se dá automaticamente. O uso da ferramenta cinematográfica exige conhecimentos de Bioética Narrativa: possibilidade de acesso à pluralidade da realidade e diversidade de percepções; exploração de experiências variadas fugindo do positivismo puro; imaginação como forma de conhecer e aprofundar a realidade; experimentação do desconhecido; produção de um 'mundo do texto', que se dá quando a obra encontra seu leitor, reconfigurando-o; possibilidade de diálogo entre o saber do filme e o do espectador; e ainda, as traduções culturais, interpretação de experiências e de lugares diversos (DOMINGO, 2011). É tarefa pedagógica estar atento a tais questões, problematizando-as ou contornando-as, tendo em vista sua condicionalidade ao maior ou menor aprendizado ético proporcionado.

A criatividade inovadora do casamento entre Bioética Narrativa e Cinema tem revelado a riqueza deste campo metododológico. Da seleção da obra ao estabelecimento de uma atmofera de aproximação professores-estudantes, é preciso rigor metodológico com a própria abertura e flexibilidade da aprendizagem. Refletir e compatilhar a experiência de educação permanente em saúde de uma turma de residentes, por meio da Bioética Narrativa, é o objetivo do presente texto.

\section{MATERIAIS E MÉTODOS}


Educação permanente em saúde: uma experiência do projeto "Bioética pelas lentes do Cinema"

Este projeto de extensão foi desenvolvido pelo Núcleo de Pesquisa e Extensão em Bioética e Saúde Coletiva (NUPEBISC) da Universidade Federal de Santa Catarina (UFSC) que, desde sua fundação em 2009, desenvolve trabalhos de pesquisa, extensão e ensino alicerçados na ênfase da dimensão ético-política da formação de seus integrantes. Participam professores, pesquisadores e estudantes, da graduação ao pós-doutorado, de diferentes cursos e programas da UFSC. O Núcleo vem desenvolvendo, desde 2011, o projeto de extensão-intervenção: "Bioética pelas Lentes do Cinema". O projeto busca fomentar a reflexão sobre as questões éticas que perpassam o cotidiano da formação e do trabalho em saúde. Para tanto, emprega a análise de obras cinematográficas buscando aproximação cada vez maior com os fundamentos da Bioética Narrativa. Diversas edições do projeto já foram realizadas em parcerias com instituições de saúde. A parceria mais recente ocorreu no segundo semestre de 2016, com a Secretaria Municipal de Saúde (SMS) da Prefeitura Municipal de Florianópolis (PMF), buscando ofertar esta atividade formativa para os 47 profissionais de saúde matriculados na Residência Multiprofissional em Saúde da Família da SMS, cujo currículo prevê carga horária para uma disciplina de bioética.

O processo de preparação da intervenção para esta edição do projeto iniciou com reuniões entre os membros do NUPEBISC e a servidora do Setor de Educação da SMS, também coordenadora da Residência. Inicialmente, discutiram-se os objetivos específicos da atividade e se acordaram as temáticas que seriam abordadas nos encontros. Os membros do Núcleo selecionaram filmes que abarcassem tais temas, bem como artigos científicos que propiciassem um embasamento teórico prévio a cada encontro. Em um segundo momento, pactuaram-se os membros do Núcleo que rodiziariam a mediação das atividades como uma forma de compartilhamento de oportunidades e experiências formativas, e foram pensadas as estratégias metodológicas que seriam desenvolvidas, elaborando-se uma sequência de etapas orientadoras da atividade para cada um dos dias: acolhimento inicial; compartilhamento da ficha técnica e da sinopse da obra escolhida; apresentação do filme; orientação para em alguns minutos refletirem e registrarem, por escrito e na forma de perguntas, um ou mais problemas éticos identificados no filme; formação da roda para a etapa de análise coletiva; início do debate a partir do compartilhamento das reflexões buscando inserir o(s) problema(s) em alguns dos eixos temáticos previamente pensados pelos organizadores (Quadro 1), com o objetivo de favorecer a articulação das questões éticas práticas a fundamentos teóricos; conclusão da análise com um resgate dos principais temas e conceitos analisados; avaliação dos participantes sobre o desenvolvimento da atividade no dia; e avaliação da atividade entre os membros do NUPEBISC, buscando 
Educação permanente em saúde: uma experiência do projeto "Bioética pelas lentes do Cinema"

levantar os pontos positivos a serem reforçados e as fragilidades que demandavam modificações.

\begin{tabular}{|c|c|c|c|}
\hline Temas & Filmes & Referências & Eixos temáticos problematizadores \\
\hline 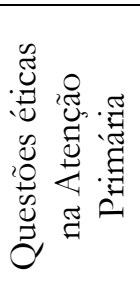 & $\begin{array}{l}\text { Série } \\
\text { 'Unidade } \\
\text { Básica- } \\
\text { primeiro } \\
\text { episódio } \\
\text { (2016) }\end{array}$ & $\begin{array}{c}\text { (Bio) ética e Estratégia de } \\
\text { Saúde da Família: mapeando } \\
\text { problemas (SIQUEIRA- } \\
\text { BATISTA, 2015) }{ }^{1}\end{array}$ & $\begin{array}{l}\text { Problemas éticos relativos a: } \\
\text { políticas públicas e o acesso aos serviços } \\
\text { de saúde; processo de trabalho e na } \\
\text { produção de saúde; } \\
\text { relações entre usuários e trabalhadores } \\
\text { da saúde. }\end{array}$ \\
\hline 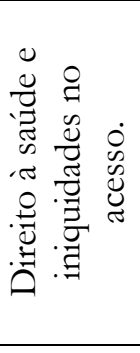 & $\begin{array}{l}\text { Um ato } \\
\text { de } \\
\text { coragem } \\
(2002)\end{array}$ & $\begin{array}{l}\text { Reflexões sobre o princípio } \\
\text { ético da justiça distributiva } \\
\text { aplicados ao sistema de saúde } \\
(\text { FORTES, 2003) }\end{array}$ & $\begin{array}{c}\text { Problemas éticos relacionados à: } \\
\text { responsabilidade do Estado na } \\
\text { implementação de políticas públicas e ao } \\
\text { acesso nos serviços de saúde; } \\
\text { distribuição dos recursos, mercado e } \\
\text { sistemas de saúde; } \\
\text { construção de sistemas de saúde com } \\
\text { equidade e responsabilidade social. }\end{array}$ \\
\hline 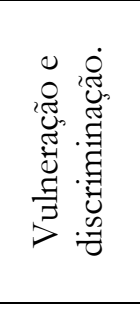 & $\begin{array}{l}\text { Ó pai, ó } \\
(2007)\end{array}$ & $\begin{array}{l}\text { Preconceito e discriminação } \\
\text { como expressões de violência. } \\
\text { (BANDEIRA; BATISTA, } \\
\text { 2002) }{ }^{3} \text {. Vulnerabilidade e } \\
\text { vulneração: população de rua, } \\
\text { uma questão ética. (SOTERO, } \\
\text { 2001) }{ }^{4} \text {. }\end{array}$ & $\begin{array}{l}\text { O Estado e as políticas públicas: sua } \\
\text { ação junto aos vulnerados; relações } \\
\text { entre a discriminação, a violência e a } \\
\text { vulneração; problemas éticos no } \\
\text { processo de trabalho e na produção de } \\
\text { saúde. }\end{array}$ \\
\hline 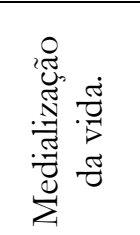 & $\begin{array}{l}\text { Nise, no } \\
\text { coração } \\
\text { da loucura } \\
(2016)\end{array}$ & $\begin{array}{c}\text { Ética e Medicalização. } \\
\text { (Módulo Curso Gestão da } \\
\text { Assistência Farmacêutica } \\
(\text { CAPONI; BRZOZOWSKI, } \\
\text { 2013) }{ }^{5} \text {. }\end{array}$ & $\begin{array}{l}\text { Interferências nas relações entre } \\
\text { usuários e profissionais; } \\
\text { institucionalização do sofrimento } \\
\text { mental; práticas em saúde mental. }\end{array}$ \\
\hline
\end{tabular}

Quadro 1 - Filmes, referências bibliográficas e eixos temáticos para os temas da edição do projeto desenvolvido com os residentes da Prefeitura Municipal de Florianópolis, em 2016.

No primeiro dia de encontro, os residentes foram recebidos e convidados a sentar nas cadeiras dispostas em roda - seguindo o Método da Roda (CAMPOS, 2003), em duas diferentes salas, uma vez que o sucesso deste tipo de atividade depende em parte da

\footnotetext{
${ }^{1}$ SIQUEIRA-BATISTA, R.; et al. (Bio)ética e Estratégia Saúde da Família: mapeando problemas. Saude soc, v.24, n.1, pp.113-128, 2015.

${ }^{2}$ FORTES, P.A.deC. Reflexões sobre o princípio ético da justiça distributiva aplicados ao sistema de saúde. In: FORTES, P. A. de C.; ZOBOLI, E. L. C. P. Bioética e saúde pública. São Paulo:Edições Loyola, 2003.

${ }^{3}$ BANDEIRA, L,; BATISTA, A. S. Preconceito e discriminação como expressões de violência. Rev. Estud. Fem., v.10, n.1, pp.119-141, 2002.

${ }^{4}$ SOTERO, M. Vulnerabilidade e vulneração: população de rua, uma questão ética. Revbioét., 2001, 19(3):799-813.

${ }^{5}$ CAPONI, S. N. C; BRZOZOWSKI, F. S. Ética e Medicalização. Módulo Curso Gestão da Assistência Farmacêutica EaD, $2^{\mathrm{a}}$ ed, 2013.
} 
Educação permanente em saúde: uma experiência do projeto "Bioética pelas lentes do Cinema"

possibilidade de todos terem a oportunidade de se expressar. Uma dinâmica inicial de reconhecimento auxiliou os facilitadores a perceber alguns das características pessoais dos participantes, os valores mais estimados pelo grupo, bem como nível de interação entre os presentes. Em seguida, apresentou-se o projeto "Bioética pelas Lentes do Cinema", seguido da pactuação das atividades e dos compromissos necessários ao bom aproveitamento, com destaque à corresponsabilização e participação ativa de cada membro do grupo na construção de um espaço verdadeiramente ético e educativo.

A introdução da temática bioética se deu a partir do conhecimento prévio dos participantes sobre os conceitos de moral e ética, e da apresentação e discussão de um vídeo facilitador: "Ser ou não ser: ética e indiferença", de Viviane Mosé (2005). A partir deste, buscou-se diferenciar ambos os conceitos e incluir diversos outros a eles relacionados. Tratava-se assim de possibilitar a compreensão e a ampliação de alguns aspectos importantes que acompanhariam as discussões do grupo. Na sequência, foi apresentado e discutido o filme selecionado. Neste processo, os facilitadores buscavam se posicionar como estimuladores da participação, mediadores dos diferentes olhares, e principalmente, resgatar os conceitos teóricos dos textos, de forma a favorecer que os participantes pudessem articulá-los, por si próprios, aos fatos e valores apresentados em cada filme e identificados em seus cotidianos. E como toda análise ética deve incluir a compreensão dos fatos sobre os quais estão montados valores, sobre os quais se determinam deveres (GRACIA, 2000), o grupo era orientado a pensar nos deveres éticos suscitados a cada filme analisado.

\section{RESULTADOS E ANÁLISES}

As temáticas abordadas geraram importantes reflexões. No quadro 2, apresenta-se uma síntese das principais problematizações realizadas.

\begin{tabular}{c|c} 
Temas & Problematizações \\
\hline
\end{tabular} 


\begin{tabular}{|c|l|}
\hline & $\begin{array}{l}\text { - Até que ponto um profissional de saúde pode decidir onde começa ou termina o seu } \\
\text { trabalho? }\end{array}$ \\
- É justo um médico abdicar tratar um paciente? Seria uma desresponsabilização? \\
- Como intervir ao notar comportamentos de violência simbólica entre usuários?
\end{tabular}

Quadro 2 - Principais problematizações dos temas discutidos na edição do projeto desenvolvido com os residentes da Prefeitura Municipal de Florianópolis, em 2016.

As avaliações evidenciaram que as atividades alcançaram os resultados esperados. A maioria dos residentes considerou excelente o planejamento das atividades, que o método empregado foi adequado e que a dinâmica desenvolvida foi boa. Afirmaram que o projeto contribuiu significativamente para sua formação, especificamente, para o desenvolvimento de sua capacidade crítica e reflexão, considerando ser uma atividade necessária para a residência. Embora a maioria tenha relatado pequeno interesse inicial, reportaram aumento ao longo dos encontros, com metade da turma considerando ter obtido um alto aproveitamento. Apesar das avaliações positivas por parte dos residentes e facilitadores, 
Educação permanente em saúde: uma experiência do projeto "Bioética pelas lentes do Cinema"

concordou-se que o grupo foi resistente à leitura dos textos recomendados. Entendendo a docência como lugar propício para a experimentação, indagação e transformação, foram pensadas estratégias de estímulo à reflexão. Assim, a equipe reforça seu papel mediador, auxiliando na condução de um discurso verdadeiro - porque próprio ao indivíduo. Daí pra frente cabe ao "estudante" o esforço de se dedicar, com vigor, a descobrir quais discursos já não servem e quais incitam a agir eticamente (FISCHER, 2009). O baixo interesse de alguns, expresso nas avaliações ou percebido pelo absenteísmo nos encontros, contradiz questões afirmadas por outros, como "os temas de debate eram muito pertinentes ao dia a dia de trabalho em saúde", "foram aulas sensacionais" e "transmitiam o conhecimento de forma prática, visual'. Na construção do conhecimento, trava-se uma 'luta' contra a propensão espontânea em manter-se em uma zona de conforto. "O ser humano adquire o desejo de conhecer na medida em que estuda, trabalha, vive. O mesmo se dá na pósgraduação" (NAMEN; GALAN JR., 2011, p.1617). Neste sentido, observou-se o desenvolvimento dos residentes quanto à profundidade de suas reflexões, à medida que se abriam para o processo e se apropriavam de conceitos e método propostos, confirmando a importância da experimentação e dos fundamentos empregados.

Alguns residentes consideraram que o método deveria proporcionar "maior tempo de debate" e "sanar mais as dúvidas e angústias dos participantes". As alternativas propostas - apresentar somente partes do filme ou solicitar que se assista ao filme previamente, já haviam sido experimentadas no Núcleo, e apesar de estender o tempo de diálogo, correm o risco de limitarem o fio condutor emocional-racional que a obra estimula. Ao mesmo tempo, entende-se que tais angústias são inerentes à formação ética, pois esta implica desconforto ao nos confrontar com os problemas morais cotidianos. Esse 'despertar' da consciência é um caminho de emoção e racionalização indispensável que se inicia em nós e quando compartilhado tem poder de humanizar. A dificuldade de se fugir do hábito da prescrição moral para uma formação autônoma em valores é uma barreira a ser transposta, onde a inquietação e o desconforto gerados são indicadores processuais.

Os residentes solicitavam formas de 'melhorar' o debate, sugerindo "perguntas norteadoras" e "acesso prévio aos eixos temáticos", numa aparente busca por simplificar ou facilitar o caminho de 'aprendizagem' que nada tem haver com a tarefa filosófica crítica de questionar os discursos e a ordem vigente, ocupando-nos de nós mesmos (FISCHER, 2009). Para Gracia (2000), a atitude ético-pedagógica verdadeiramente comprometida com a transformação do ser reside na possibilidade de construir novas atitudes a partir da mudança das perspectivas e formas de se abordar as questões morais. Esse novos olhares 
Educação permanente em saúde: uma experiência do projeto "Bioética pelas lentes do Cinema"

precisam ser experimentados, sendo o docente facilitador desse movimento, como no método maiêutico que tem no estímulo ao questionamento uma de suas ferramentas. Este exercício de registrar os problemas éticos percebidos nos filmes em forma de perguntas revelou-se de grande dificuldade para os participantes, demonstrando quão incipiente é nosso conhecimento acerca do mundo dos valores e da moral. Esta constatação foi referendada pelos depoimentos que destacaram a 'novidade' que foram as quatro "aulas" de bioética e cinema, nem tanto pelo método diferenciado, mas pelo estímulo à reflexão dos problemas diários. De fato, a desatenção e a desvalorização da dimensão ética da formação profissional em saúde podem ser consideradas o maior déficit educativo da academia (GRACIA, 2004).

As considerações de que os encontros haviam sido "diferentes de tudo que já tiveram no curso", revelam aspectos do ambiente acadêmico hegemônico, que por não abrir espaço para a crítica e o diálogo tende a individualizar os estudantes e hierarquizar os saberes. Alguns estudantes chegam citar o ambiente acadêmico como 'hostil ou ameaçador', o que inviabiliza a formação ética, pois depende da vivência de valores humanizadores que sejam estimulados por um ambiente flexível, democrático e libertador. Por vezes o estímulo constante dos facilitadores ao diálogo e à troca de experiências foi visto como impositivo por aqueles que se sentiram "obrigados a falar" ou por aqueles que "sentiram que contribuíram pouco por não terem um conhecimento prévio sobre os temas". Entende-se que o conhecimento crítico é sempre novo, já que "o questionamento acrescenta-lhe alguma dimensão, algum olhar, alguma preocupação que antes não existia” (DEMO, 2000 apud NAMEN; GALAN, 2011, p. 1612).

A produção cinematográfica faz com que a perspectiva do telespectador deixe de ser uma só, sendo a composição dessas diferentes percepções por meio do diálogo entre os participantes imprescindível na compreensão da realidade (MERCADÉ, 2005). Por isso a importância do diálogo e da dialética nos espaços de formação ética, compreendendo que a vivência nestes ambientes de questionamentos é que pode levar ao desenvolvimento de habilidades comunicativas necessárias à práxis eticamente comprometida.

Histórias suscitam interesse, perguntas, anseios e compreensões, servindo, por vezes, como bálsamos sobre a complexidade de nossas vidas e de nossos cotidianos. As narrativas, quando munidas de reflexão crítica permitem o afloramento do humano em nós - essa capacidade de melhorar-se não somente como indivíduo, mas como coletivo que se importa e cuida um dos outros - uma tarefa essencialmente ética. 
Educação permanente em saúde: uma experiência do projeto "Bioética pelas lentes do Cinema"

\section{CONSIDERAÇÕES FINAIS}

A experiência formativa aqui analisada foi uma via de mão dupla, pois ao mesmo tempo em que buscou promover o desenvolvimento da capacidade de reflexão e crítica dos residentes, fomentou a formação ético-pedagógica dos membros do próprio Núcleo. Nesse sentido, gerou ainda a certeza de que o referencial da Bioética Narrativa precisa ser mais bem compreendido e compartilhado, a fim de que todo o potencial do projeto de extensão e intervenção "Bioética pelas lentes do cinema" seja disparado a cada nova edição.

\section{REFERÊNCIAS}

DOMINGO, Tomás. Bioética y Cine: De la narración a la deliberación. Madrid: San Pablo, 2011.

DOMINGO, Tomás; FEITO, Lydia. Bioética narrativa. Madrid: Escolar y Mayo, 2013.

FINKLER, Mirelle; CAETANO, João Carlos; RAMOS, Flávia Regina. O cuidado éticopedagógico no processo de socialização profissional: por uma formação ética. Interface Comunic., Saude, Educ., v.16, n.43, p.981-93, out./dez., 2012.

FISCHER, Rosa Maria Bueno. Docência, cinema e televisão: questões sobre formação ética e estética. Rev. Bras. Educ., v.14, n.40, p.93-102, abr 2009.

GRACIA, Diego. Fudamentacion y enseñanza de la bioetica. Buho: Bogotá, 2000. Como arqueros al blanco: estudios de bioética. Madrid: Triacastela; 2004.

MARTÍNEZ, Miquel Martínez; ESTRADA, María Rosa Buxarrais; BARA, Francisco Esteban. La universidad como espacio de aprendizaje ético. Rev. Iberoam. Educ., n.29, p. $17-42,2002$.

MERCADÉ, Antonio Blanco. Bioética clínica y narrativa cinematográfica. Rev. Med Cine., n.1, p.77-81, 2005.

NAMEN, Fatima.; GALAN Jr., João. Reflexões sobre a educação de profissionais da área de saúde. Ciência \& Saúde Coletiva, v.16, spl.1, p. 1611-19, 2011. 